\title{
Configuração identitária de enfermeiros de um serviço de atendimento móvel de urgência
}

\author{
Identity's configuration of nurses of a mobile emergency care service
}

Configuración de la identidad de enfermeros de un servicio de atención móvil de urgencia

\author{
Vanessa Luciana Lima Melo de Avelar', Kely César Martins de Paiva' \\ 'Faculdade Novos Horizontes. Programa de Mestrado Acadêmico em Administração. Belo Horizonte, MG
}

Submissão: 14/09/2009

Aprovação: 14/08/2010

\section{RESUMO}

O objetivo deste estudo foi analisar como tem se configurado a identidade de enfermeiros Que trabalham em um Serviço de Atendimento Móvel de Urgência (SAMU), baseando-se no modelo de Dubar. Procedeu-se a um estudo qualitativo, cujos dados foram coletados, principalmente, por meio de entrevistas realizadas com enfermeiros e outros membros da equipe, e submetidos à análise de conteúdo. Quanto à identidade do enfermeiro, os resultados apontam para um sujeito diferenciado, experiente, solitário, mais próximo das atividades assistenciais, em busca de capacitação e reconhecimento, envolto em relações de trabalho complexas. Diante das limitações da pesQuisa e de Questões Que surgiram no seu processo de consecução, sugestões para investigações futuras são alinhadas ao final do artigo.

Descritores: Enfermeiras; Enfermeiros; Enfermagem em emergência; Serviços médicos de emergência; Crise de identidade.

\section{ABSTRACT}

This study considers the configuration of the identity of nurses working in a Mobile Emergency Care Service, based on the model of Dubar. This is a Qualitative study, in which data were collected mainly through interviews, with nurses and other team members, and analyzed according to the technique of content analysis. About the identity of the nurse, the results point to a different subject, experienced, lonely, closer to the welfare activities, in search of training and recognition, wrapped in complex labor relations. Due the limitations of research and the issues that emerged in the research process, suggestions for future research are aligned at the end of the article.

Key words: Nurses; Nurses male; Emergency nursing; Emergency medical services; Identity crisis.

\section{RESUMEN}

El objetivo de este estudio fue analizar cómo se ha configurado la identidad de los enfermeros que trabajan en un Servício de Atendimiento Móvil, baseado en el modelo de Dubar. Procede un estudio de carácter cualitativo, cuyos datos fueron recogidos, principalmente, por médio de entrevistas realizadas con enfermeros y otros miembros del grupo, y analizados a luz de la técnica de análisis del contenido. En cuanto a la identidad del enfermero, los resultados apuntan para un sujeto diferenciado, experiente, solitário, más próximo de las actividades asistenciales, en busca de capacitación e reconocimiento, envuelto en relaciones de trabajo complejas. Delante de las limitaciones de pesquisas y de cuestiones que surgieron en el proceso continuación; sugestiones para investigaciones futuras son delineadas al final del artículo.

Descriptores: Enfermeras; Enfermeros; Enfermería de urgência; Servicios médicos de urgência; Crisis de Identidad.

\footnotetext{
AUTOR CORRESPONDENTE Kely César Martins de Paiva. Rua alvarenga Peixoto, 1270. CEP 30180-121. Belo Horizonte, MG.

E-mail: kely.paiva@unihorizontes.br
} 


\section{INTRODUÇÃO}

O estudo da identidade profissional tem se destacado pelas constantes transformações do mundo contemporâneo e a enfermagem se insere neste contexto. A conquista progressiva de novas funções, competências, autonomias, refletem a tentativa de seus agentes em acompanhar padrões de formação cada vez mais elevados e diferenciados, caracterizando-na como uma profissão em transição. Em face das constantes mudanças por Que vêm passando, sua trajetória identitária tem-se transformado num empenho pessoal pela construção de uma "identidade positiva" e na Quebra do paradigma de pouca valorização e autonomia historicamente construídos ${ }^{(1)}$. Neste âmbito, vários autores referem a forte ligação da identidade histórica do enfermeiro com a relação de gênero predominantemente feminina, conotação religiosa e pouca valorização profissional ${ }^{(1-4)}$. A tentativa de demarcação do poder médico no ato médico e a dicotomia entre o processo de cuidar e o de curar refletem algumas das indefinições Que envolvem a crise de identidade por Que vem passando este profissional ${ }^{(1,3)}$.

No curso destas mudanças, há de se ressaltar o crescimento e a evolução desta profissão nos últimos anos, tanto pela abertura de espaços não ocupados anteriormente Quanto pelo desenvolvimento de especializações Que aprimoram sua prática ${ }^{(5)}$. Em contrapartida, a incorporação de novas tecnologias, a alteração dos padrões socioeconômicos e de saúde-doença, e as exigências crescentes da sociedade por uma melhor assistência, muitas vezes, fazem com Que o exercício de suas funções ultrapasse sua formação acadêmica ${ }^{(1)}$.

Apesar da expansão dos cursos de graduação em Enfermagem e da reformulação porQue seus currículos vêm passando, privilegiando a formação de profissionais críticos, reflexivos, criativos e com capacidade de liderança, autonomia e competência técnica ${ }^{(6)}$, eles se encontram, muitas vezes, desvinculados da realidade prática dos contextos organizacionais. Nesse sentido, como principais tendências das transformações curriculares, destaca-se: atuação no âmbito pré-hospitalar; aprendizagem baseada em problemas e evidências; transdisciplinariedade; e bioética ${ }^{(7)}$.

No Que tange à assitência pré-hospitalar brasileira, a crescente demanda de vítimas de acidentes automobilísticos e de violência inter-pessoal são protagonistas de um cenário de pouca estruturação e padronização dos serviços de urgência. Em face desta contingência, o Ministério da Saúde criou a Política Nacional de Atenção às Urgências, pela Portaria n. 2.048, de 5 de novembro de 2002 com o propósito de melhor definir os serviços já existentes e ampliá-los em nível nacional ${ }^{(8)}$. Assim, os serviços de urgência e emergência hospitalar, as unidades básicas de saúde, os ambulatórios, os prontosocorros e os serviços de atendimento móvel de urgência (SAMU) são contemplados por esta legislação. Apesar de ser um serviço novo, a importância dos SAMU tem sido destacada, considerando-se seus impactos positivos no prognóstico dos doentes atendidos ${ }^{(9)}$.

Observa-se Que, em meio a essa nova conjuntura de assistência à saúde nos serviços de urgência e emergência Que, para além da assistência hospitalar, o atendimento no domicílio e no local de ocorrência dos acidentes e violências é uma realidade recente no contexto de atuação do enfermeiro.

O crescimento dos SAMU torna evidente a necessidade de formar profissionais Qualificados e, considerando-se sua ampliação em nível nacional, o número de enfermeiros preparados para atuar nesta área ainda é restrito ${ }^{(10-1)}$. Acrescente-se o fato de Que as urgências não constituem especialidade médica ou de enfermagem e Que a atenção dada nos cursos de graduação ainda é considerada insuficiente ${ }^{(8)}$.

Considerando-se a pluralidade da equipe que ali trabalha e dos diferentes contextos de atuação, infere-se Que talvez não exista uma só forma de ser enfermeiro, daí a necessidade deles Questionarem a sua própria identidade ${ }^{(1)}$. A possibilidade de se manifestar como ser e trabalhador no cotidiano de trabalho estão intimamente relacionadas com a constituição de sua identidade ${ }^{(12)}$.

Importa ressaltar Que, apesar do crescimento das áreas de atuação dos enfermeiros e de todo o arcabouço legal Que os rege, falta clareza acerca de suas atribuições, principalmente em serviços de origem recente, como os SAMUs.

Admite-se Que a atuação do enfermeiro contribui sobremaneira para os resultados do processo de assistência, de gestão de materiais e equipamentos, de comunicação com outros atores sociais e, consequentemente, da atuação do próprio SAMU. A forma como ele se percebe neste contexto específico pode determinar sua atuação. Daí a importância de aprofundar as Questões relativas à sua identidade. A identidade é configurada na percepção de si mesmo (identidade real) e do outro (identidade virtual) e portanto, apesar do senso de individualidade, é correlativa ao contexto de atuação, às experiências cotidianas, à interação e reconhecimento dos demais atores sociais ${ }^{(13)}$. A comparação perante os membros do grupo social relacional, as relações de poder, o processo motivacional e a construção de uma autoestima positiva contribuem para a construção da identidade no trabalho ${ }^{(14)}$.

Portanto, depreende-se Que a identidade do enfermeiro assume significados que dependem do seu papel e do grupo em Que está inserido. Assim, pretende-se especificamente analisar como tem se configurado as identidades real e virtual do enfermeiro Que trabalha especificamente em unidades de suporte avançado de um SAMU.

\section{REFERENCIAL TEÓRICO}

\section{Identidade: algumas perspectivas de análise}

A identidade tem sido apresentada como um conceito amplo, complexo, adotado frequentemente para compreender a inserção do sujeito no mundo e sua relação com o outro. Associa-se comumente como algo individual, singular, atributo de caracteres próprios e exclusivos como, por exemplo, a data de nascimento, filiação e a impressão digital ${ }^{(4)}$.

Apesar da conotação de singularidade, trata-se de um processo dinâmico, em constante construção e reconstrução $0^{(13,15)}$, cujas experiências individuais de socialização constituem seu principal referencial de formação ${ }^{(16,17)}$. Várias perspectivas de análise ou níveis de identidade são descritas na literatura e, apesar de distintas, se complementam.

No tocante à identidade pessoal, envolve a construção do "autoconceito", ou "conceito de si mesmo", por meio de relacionamentos sociais e do desempenho de papéis, e ocorre em todas as fases da vida do indivíduo. Já a identidade social diz respeito à construção do autoconceito dentro de um ou vários grupos e 
pode orientá-lo e legitimá-lo mediante o reconhecimento e vinculação social. Quanto à identidade no trabalho, esta é referenciada como uma construção do eu pela atividade Que o indivíduo realiza e pelas pessoas com Quem se relaciona no trabalho. Ocorre na juventude, na idade adulta e, até mesmo na aposentadoria, e contribui para a formação de sua identidade pessoal como fator motivacional. Por último, a identidade organizacional refere-se à construção do conceito de si vinculado à organização na Qual trabalha. "O indivíduo identifica-se com o grupo ou grupos aos Quais pertence, com o trabalho Que realiza e com a organização à Qual pertence"(17). No Que tange à identidade profissional ou coletiva, baseia-se em traços ou características comuns a todos Que exercem determinada atividade $^{(4)}$.

Assim, a identidade é um fenômeno Que emerge da interação dialética entre indivíduo e sociedade, num processo de interiorização, em Que a pessoa é introduzida no mundo objetivo de uma sociedade ou setor dela. Apesar de ser formada por processos sociais, pode ser modificada ou, mesmo, remodelada pelas suas relações ${ }^{(16)}$. Este processo de socialização inicia-se na infância, na transmissão de valores pelos pais e parentes mais próximos, pertencentes ao único mundo perceptível à criança. Nesta, os saberes de base são adouiridos, por exemplo, a alfabetização, a leitura, linguagem leitura e escrita. A incorporação desses saberes é mediada pela relação da família com a escola e da criança com os adultos e assegura a socialização primária e, consequentemente, a posse subjetiva do eu e seu mundo. Entretanto, o indivíduo só se faz membro da sociedade a partir da compreensão de seus semelhantes e da "apreensão do mundo como realidade social dotada de sentido"(16). A inserção do indivíduo em outros setores, determinados pela divisão do trabalho e da distribuição social do conhecimento com a aquisição de vocabulários e funções específicas relacionados ao cotidiano de trabalho, cincunscreve a socialização secundária. Em decorrência da experiência vivida no cotidiano e no contexto de mudanças Que tem marcado nossas sociedades, a socialização secundária pode ser considerada como mais volátil Que a socialização primária ${ }^{(14)}$. Considera-se Que as identidades são mutáveis ao longo dos tempos e que a reconstrução das identidades nacionais e éticas no mundo globalizado emerge novos movimentos sociais ${ }^{(18)}$.

A experiência vivenciada no ambiente de trabalho é fundamental para a formação das identidades sociais fazendo com Que as organizações se tornem espaços privilegiados de construção de identificações ${ }^{(19)}$. Outro setor considerado como elemento decisivo no processo de construção identitária é a escola. Nesta, tenta-se passar ao indivíduo "aquilo que ele deve ser"(1). Todo o exposto parece desvelar a complexidade do estudo sobre identidade e a diversidade de perspectivas teóricas para sua análise. Para fundamentar a presente investigação, optou-se por uma aproximação dos mecanismos de identificação propostos por Dubar ${ }^{(13)}$ como constituintes fundamentais para analisar as identidades real e virtual dos enfermeiros no contexto específico de um SAMU. Este autor ${ }^{(13)}$ parte do pressuposto de Que a representação Que os outros possuem do sujeito é fundamental e a constituição do sentido pessoal de pertença e Que este é relevante na configuração identitária. Os valores de seu grupo relacional são interiorizados e guiam as condutas do indivíduo. Daí, o sujeito passa a exercer um papel Que considera ser útil e reconhecido ${ }^{(13)}$. Portanto, um dos pontos de partida proposto como estratégia para a análise do processo de configuração identitária é Que, além do indivíduo, seu grupo de pertença também seja investigado. Propõe-se a estudar não apenas a representação Que o indivíduo possui do seu papel, mas, fundamentalmente, a Que possui do grupo em Que se inclui, vista de seu interior ${ }^{(13)}$. O modelo de análise adotado nesta pesquisa parte do princípio de Que o eu é dividido em um ser individual e um ser social, reflexo de uma dualidade imposta pela sociedade Que implica a articulação entre dois processos identitários heterogêneos. Este nunca é dado, e, sim, construído e reconstruído ${ }^{(13)}$. A chave do processo de construção das identidades sociais se dá na articulação entre duas transações: a objetiva e a subjetiva. A transação objetiva, também denominada "transação externa" ${ }^{(13)}$, ocorre entre o indivíduo e os outros significativos e visa acomodar a identidade para si e para o outro. A "transação interna" ao indivíduo procura assimilar a identidade para o outro à identidade para si. Também denominada "transação subjetiva", constitui-se no segundo mecanismo central do processo de socialização concebido como produto de identidades sociais.

No contexto de trabalho, os indivíduos se vêem obrigados a estabelecer relações estáveis ou duráveis com seu grupo e com seu chefe, bem como a partilhar atividades organizacionais, cujo investimento pode implicar o reconhecimento recíproco destes sujeitos. Portanto, a transação objetiva envolve relações de poder, normas de comportamento, assim como cultura, afinidades e valores organizacionais ${ }^{(13)}$. Para identificar a si próprio, o indivíduo utiliza os atos de pertença, ou seja, categorias de significado Que exprimem "Que tipo de homem (ou de mulher) você Quer ser". Já a identidade para o outro, ou identidade virtual, é definida pelas pessoas com Que o indivíduo se relaciona, a partir de categorias que definem Que tipo de homem ou mulher você é, ou seja, os atos de atribuição(13).

Nesses termos, o processo identitário biográfico descrito por Dubar $^{(13)}$ é definido como uma construção temporal sucessiva de identidades sociais e profissionais, a partir das categorias oferecidas por instituições como família, escola, mercado de trabalho e empresa. 
O modelo proposto por Dubar ${ }^{(13)}$, cujas análises dos processos de identificação e das consequentes identidades real (para si) e virtual (para o outro) convergem na configuração identitária, encontra-se descrito e esquematizado no Quadro 1.

A transição vivenciada pela saída das instituições de formação e sua relação com o mercado de trabalho constitui um momento essencial para a construção da identidade autônoma. Há de se considerar Que a identidade profissional de base pode constituir não só a identidade no trabalho, mas também uma projeção de si no futuro e a concretização do aprendizado ${ }^{(13)}$. Para legitimar suas capacidades em um determinado contexto de trabalho, muitas vezes o indivíduo se empenha em obter certificações e em desenvolver relações de identificação com seus pares. Uma especialização, por exemplo, pode representar um ato significativo da identidade virtual e a identificação pelo outro de suas competências ${ }^{(13)}$.

\section{O Serviço de Atendimento Móvel de Urgência e especificidades do profissional enfermeiro}

$\mathrm{O}$ atendimento pré-hospitalar nas últimas décadas tem sido amplamente discutido e remodelado por autoridades de várias esferas governamentais ${ }^{(20)}$. Regulamentado e assegurado por lei, ele passou por uma série de modificações, Que tiveram como conseQuência a padronização do serviço em nível nacional. É uma modalidade de atenção da área da Saúde instituída pelo Ministério da Saúde e responsabilizada pelo atendimento de pacientes com agravos clínicos, traumáticos, obstétricos e psiquiátricos. A assistência prestada é desencadeada por um solicitante via telefone, pelo número gratuito 192, vinculado a uma Central de Regulação e destina-se ao local de sua ocorrência Que, pode ser um domicílio ou via pública, dentre outros ${ }^{(8)}$.

Apesar das restrições impostas em termos de cobertura da população e das dificuldades vivenciadas em sua prática, principalmente no Que concerne à disponibilidade de profissionais capacitados, o SAMU responde diariamente por uma grande demanda de atendimentos e emprega um número crescente de profissionais. Atualmente, ele é responsável pela maior parte dos encaminhamentos aos serviços de saúde. Sua rede nacional conta com 144 serviços, Que envolvem 1.163 municípios e mais de 100 milhões de usuários potenciais ${ }^{(21)}$.

O SAMU brasileiro foi baseado na modalidade de atendimento de resgate francês. Por isso, tem na Central de Regulação de Urgências e Emergências seu "elemento ordenador e orientador" e no médico da Central de Regulação, seu "sujeito nuclear"(8). As funções dos profissionais da saúde, bem como de toda a equipe Que trabalha direta ou indiretamente no atendimento pré-hospitalar, só foram definidas formalmente a partir da Portaria n. 2048 do Ministério da Saúde ${ }^{(8)}$.

Nesses serviços, o enfermeiro, o médico-intervencionista e o motorista-socorrista compõem a equipe das Unidades de Suporte Avançado de Vida (USA). Juntos, são responsáveis pelos atendimentos Que envolvem procedimentos de maior complexidade. Esses atendimentos são realizados em domicílios, vias públicas, instituições hospitalares e durante o transporte dos pacientes. Acredita-se Que nestes atendimentos o enfermeiro pode reafirmar sua condição de enfermeiro assistencial, contrapondo o cotidiano de trabalho de muitas instituições hospitalares.

Os profissionais das equipes de saúde Que atuam nos serviços de emergência são peças fundamentais no processo de cuidar. Para tal, atributos como competência, habilidade motora, criatividade, e sensibilidade são exigidos. Em termos críticos, o cuidar em emergência exige mais do Que conhecimento técnico, ou seja, conta também com a experiência de seus profissionais, o seu "saberfazer"(22).

No caso específico do enfermeiro e de suas práticas no cuidar em situações de urgência e emergência, destacam-se, dentre as suas funções: a identificação de sinais e sintomas de gravidade, a interpretação destes, a utilização de todos os recursos disponíveis e a identificação da possibilidade de transmissão de doenças infectoparasitárias para a equipe e para outros clientes, dentre outras. No Que se refere às dificuldades encontradas pelos enfermeiros nos serviços de atendimento pré-hospitalar, além da falta de experiência e da pouca formação, destaca-se a adaptação a um novo e diferente ambiente de trabalho e o confronto com a vulnerabilidade social e situações de violência interpessoal, inclusive agressões verbais dirigidas aos profissionais de saúde ${ }^{(23)}$. A experiência prévia em serviços de urgência e a busca por capacitação específica têm amenizado tais dificuldades ${ }^{(24)}$.

\section{MÉTODO}

Procedeu-se a uma pesquisa de caráter Qualitativo ${ }^{(25)}$. Seu desenvolvimento teve como locus o SAMU de um município mineiro, Que funciona 24 horas por dia, todos os dias da semana e Que disponibiliza à sua população adscrita 25 unidades de suporte básico (USB) e 5 unidades de suporte avançado (USA), as Quais atuam em conjunto com o Corpo de Bombeiros, no caso de retirada de vítimas das ferragens, com a Polícia Militar e a Polícia Rodoviária. Suas unidades estão localizadas de forma estratégica, considerandose a distribuição espacial do município e a facilidade de acesso por vias rápidas.

Atualmente, a equipe de enfermeiros encontra-se subdividida em 5 Unidades de Suporte Avançado de vida e conta com atuação de aproximadamente 46 profissionais, Que trabalham em escala de plantão. A elaboração de suas escalas considera uma carga horária semanal de trabalho Que varia entre 20 e 24 horas semanais, dependendo do vínculo empregatício, perfazendo uma média de 6 a 9 plantões por mês. Quanto aos sujeitos secundários, a eQuipe é composta por aproximadamente 48 médicos, mais de 100 motoristas-socorristas e centenas de técnicos de enfermagem. Estes últimos compõem apenas as equipes de Suporte Básico de Vida (SBV) e os motoristas socorristas trabalham tanto nas Unidades de Suporte Básico (USB) Quanto nas Unidades de Suporte Avançado (USA). O médico trabalha tanto nas USA quanto na Central de Regulação.

As unidades de observação foram constituídas de enfermeiros e não-enfermeiros - médicos intervencionistas, motoristas socorristas e técnicos de enfermagem - do SAMU abordado e a unidade de análise foi a identidade de enfermeiros das unidades de suporte avançado (USA) de vida deste mesmo serviço.

Com base nos pressupostos de Dubar ${ }^{(13)}$, Que assinala que a identidade é configurada na percepção de si mesmo (identidade real) e do outro (identidade virtual), os enfermeiros Que trabalham nas unidades de suporte avançado constituíram os sujeitos nucleares e os profissionais Que trabalham direta ou indiretamente com eles, 
os sujeitos secundários ou relacionais.

A coleta de dados se deu por meio de levantamento documental de fontes internas, de Questionários sociodemográficos e de entrevistas com roteiros estruturados, as Quais foram realizadas com enfermeiros e não-enfermeiros, o Que configurou uma triangulação entre dados ${ }^{(26-27)}$.

A análise das entrevistas obedeceu à técnica de Análise de Conteúdo ${ }^{(28)}$. Sublinha-se que os sujeitos entrevistados foram selecionados aleatoriamente e a Quantidade de entrevistas realizadas obedeceu ao método de saturação de dados, cujo critério considera a reincidência e relevância dos relatos ${ }^{(28-29)}$.

O projeto desta pesQuisa foi aprovado pela gerente do SAMU no eual o estudo foi realizado e, posteriormente, submetido e aprovado pelo Comitê de Ética em Pesquisa da Secretaria Municipal de Saúde a Que se encontra vinculado, sob o protocolo $n^{\circ}$ 052/ 2008. Desta forma, objetivou-se atender às exigências da Resolução 196/96 do Ministério da Saúde, Que regulamenta a pesquisa em seres humanos ${ }^{(30)}$. Aos sujeitos do estudo foi fornecido um Termo de Consentimento Livre e Esclarecido, com as devidas informações Quanto aos objetivos da pesquisa, ao anonimato, ao consentimento escrito e à permissão para utilização do gravador, com o esclarecimento prévio de possíveis dúvidas.

\section{RESULTADOS E DISCUSSÃO}

\section{Dados demográficos dos sujeitos}

Em termos demográficos, foram entrevistados 20 profissionais, sendo contabilizados 11 sujeitos nucleares (enfermeiros) e nove secundários (Quatro motoristas-socorristas, três médicos e dois técnicos de enfermagem).

Dentre os 1 I sujeitos nucleares, Quanto ao sexo, nove são mulheres e dois são homens. Este resultado corresponde à realidade do grupo de enfermeiros do serviço, Que, no seu conjunto, atualmente, integra um total de 46 enfermeiros, sendo 42 mulheres $(91,3 \%)$ e apenas Quatro homens $(8,7 \%)$. Atenta-se para o fato de Que esta característica, profissionais predominatemente do sexo feminino, diferencia a enfermagem das outras profissões, e exerce grande influência sobre os papéis profissionais e os relacionamentos interpessoais em seus locais de trabalho ${ }^{(3)}$.

Ainda sobre os sujeitos nucleares, a faixa etária revela a presença tanto de profissionais jovens Quanto maduros no exercício de suas funções variando entre 26 a 50 anos de idade e tempo de formação acadêmica entre seis a 20 anos de conclusão.

Quanto ao vínculo institucional, dez dos onze enfermeiros entrevistados entraram nesta organização via concurso público e Quatro deles trabalharam no modelo anterior à criação do SAMU. Em relação ao tempo de trabalho no SAMU, 42,0\% encontram-se na instituição no tempo compreendido entre um a cinco anos; $33,0 \%$, de 11 a 15 anos; 8,0\%, de seis a dez anos; e 8,0\%, menos de um ano.

No Que tange ao grupo dos sujeitos relacionais, a maioria dos participantes é do sexo masculino $(66,6 \%)$, possui entre 31 e 40 anos $(62,0 \%)$ e vínculo institucional entre seis a dez anos $(44,0 \%)$. Os médicos são todos concursados e os motoristas-socorristas são vinculados a uma empresa terceirizada Que presta serviços ao município. Um dos técnicos de enfermagem é concursado e o outro firmou contrato administrativo de prestação de serviço com esta instituição. A totalidade dos sujeitos secundários antes de entrar para este SAMU possuía alguma experiência relacionada à atividade desempenhada. Mas, assim como os enfermeiros, nunca haviam trabalhado em serviço de atendimento pré-hospitalar.

\section{Serviço de Atendimento Móvel de Urgência: singularidades para os sujeitos entrevistados}

Em linhas gerais, os sujeitos nucleares e secundários desta pesquisa fazem algumas considerações sobre o SAMU em Que trabalham. A este serviço, a maioria atribui uma assistência especializada e de Qualidade, Que proporciona aos seus pacientes a agilidade necessária para preservar suas vidas antes mesmo de serem encaminhados à unidade hospitalar (E01, E02, E03, E04, E05, E08, E09, EII, El2, EI5, El6, E19, El7, El8, E19, E20).

Os entrevistados verbalizam a consciência Quanto a responsabilidade social do serviço, exemplificada pela oportunidade de se atender QualQuer pessoa, de Qualquer classe social. Suas falas, remetem aos aspectos da universalidade de acesso, na equidade e integralidade na atenção prestada Que balizam a legislação Que regulamenta este serviço. Mais do Que um traço constante, o sentimento de satisfação em poder ajudar o próximo (E01, E02, E03, E04, E06, E08, E09, El I, E12, El3, EI5, El6, EI7, E I 8) e em fazer a diferença, a convivência com os desafios e a imprevisibilidade, mais a busca por capacitação, parece traduzirse na identidade da organização e a confundir-se com a identidade dos diversos grupos sociais ${ }^{(17)}$.

O SAMU, ele satisfaz muito uma coisa da minha personalidade! Eu sou inquieta e eu gosto de surpresa. Então, nas minhas atividades profissionais sempre precisei de alguma coisa Que fosse um efeito surpresa. (E03)

A oportunidade de confrontar situações envoltas de vulnerabilidade social marca o depoimento seguinte, Quando o entrevistado um paralelo entre a responsabilidade do serviço com as diretrizes do Sistema Único de Saúde.

[...] eu penso Que é a melhor forma de se atender pré-hospitalar. O SAMU é, nesse aspecto, eu acho que ele é muito bacana, muito bonito, exatamente porQue ele leva o SUS ao cidadão, certo, a Qualquer tipo de cidadão, de uma forma absolutamente eQuânime e democrática. (E I7)

Os sujeitos nucleares e secundários fizeram comparações entre trabalhar em contexto hospitalar e pré-hospitalar. Dentre as diferenças Que mais se destacou pontuam-se: a estrutura física, o Quantitativo de profissionais, materiais e equipamentos (E04, E05, E I 5, EI6), as variações climáticas (E I4, EI6), as interferências do trânsito (E I I) e Questões relacionadas ao grau de exposição perante a população (E05, El3, El5, E 16). Acrescidos dos riscos ocupacionais físicos, Químicos e biológicos intrínsecos aos serviços de saúde, ficam expostos às situações de violência interpessoal, tão frequente em seus contextos de atuação ${ }^{(23)}$.

Outro ponto Que marca a fala dos sujeitos é Que os profissionais do SAMU não têm assegurado um horário certo de terminar um plantão, de fazer suas refeições e nem mesmo de atender suas necessidades de eliminação. O profissional Que ali trabalha deve 
estar preparado todo o momento para atender pacientes de QualQuer faixa etária (E04, E10, E15, E17).

[... porque a gente Que trabalha na ambulância, a gente pega QualQuer faixa etária. Não tem uma faixa etária: idoso, criança e jovem, né, adolescente, neném, recém-nascido. Então, você trabalha em uma faixa etária muito variada. (E I4)

A propósito da equipe de enfermagem, um sujeito secundário (EI 8) citou o distanciamento do enfermeiro dos demais integrantes da equipe de enfermagem como uma de suas principais diferenças.

Tem muita diferença. Primeiro pela distância entre a equipe e o enfermeiro. A equipe do enfermeiro no pré-hospitalar não é a equipe de enfermagem. A equipe do enfermeiro no pré-hospitalar é o médico e o motorista. Não tem a enfermagem. Fica separado e no hospital, não. Fica o enfermeiro coordenando a equipe de enfermagem. Ele representa a equipe. No pré-hospitalar isso não acontece. (EI8)

Apesar do referido distanciamento, o enfermeiro das USA se sentem mais próximos das atividades assistenciais, diferentemente de outros contextos de atuação. Esta característica delimita de certa forma um dos traços identitários destes enfermeiros.

Considerando-se Que o percurso de vida do indivíduo e sua consequente trajetória profissional permitem moldar sua identidade ${ }^{(13)}$, alguns aspectos da trajetória profissional dos sujeitos nucleares subsidiaram a categoria de análise seguinte.

Percurso da trajetória profissional de enfermeiros de um SAMU

A maioria dos enfermeiros entrevistados revela Que tiveram contato com a assistência a pacientes críticos na época da graduação em Enfermagem, principalmente nos estágios extracurriculares, Quando vivenciaram o processo de socialização e conseQuente identificação ${ }^{(16)}$.

Eu comecei muito cedo na urgência e emergência. É um serviço Que desde o princípio eu me identifieuei muito com ele, então eu comecei como acadêmica. (E04)

Quando solicitados a falar sobre sua trajetória profissional, cinco dos onze enfermeiros deixou claro Que a opção pelo curso de enfermagem foi uma alternativa em função de diversas dificuldades em frequentar o curso de sua primeira opção. Dentre as dificuldades, pontuam-se a presunção de uma condição financeira insuficiente e a não aprovação no curso de sua primeira opção.

Alguns dos entrevistados revelaram Que Quando entraram na faculdade nem sabiam o Que era ser enfermeiro. Todavia, apesar do desconhecimento inicial em relação à profissão, da falta de sentido vocacional e até mesmo da reprovação da família pela escolha, uma relação afetiva foi estabelecida já durante o processo de socialização ocorrido ainda na academia ${ }^{(13,16,19)}$.

Eu gosto muito do que eu faço. Assim, sou enfermeira com muito orgulho de saber se meu pai também acha assim muito legal. Acho muito chique. Antes ele não aceitava, no começo, né. Acho também Que pelo desconhecimento do também da profissão. Mas hoje, não; ele tem o maior orgulho de falar: "ah, minha filha é enfermeira, ah, minha filha faz doutorado". Então, assim sai contando para todo mundo, porque ele gosta muito de falar Quando está entre amigos. Então, para mim, eu me sinto realizada também profissionalmente e não me sinto nem um pouco depreciada. Não me sinto menor por não ter feito medicina. Muito pelo contrário; me sinto até mais capacitada porque a gente tem um olhar além do Que simplesmente a doença, né. Então, eu gosto muito do que eu faço. (E I0)

Quando indagados sobre como aprenderam a ser enfermeiro, os entrevistados confirmaram Que a identidade profissional só se constrói na prática, nos contextos Que permitem identificação com modelos de conduta e a comparação entre os pares relacionais ${ }^{(19)}$. A busca de uma identidade por meio da comparação com os membros do grupo social relacional ${ }^{(14,19)}$ aparece na fala de um enfermeiro entrevistado (E03).

Você tem que pensar rápido. Você tem que ter capacidade manual. Você tem que ter discernimento e tem que estar preparado do ponto de vista emocional. Você tem que ter habilidade técnica. Você tem Que ter um coeficiente intelectual muito bom. E as nossas colegas investem muito nisso. Eu acho Que as nossas colegas são as ideais. Eu não convivi com as outras. Eu não convivo com você e eu não convivo com as outras. Excepcionalmente, eu vejo alguém, mas as que iniciaram o sistema são ideais, né? (E03)

A maior parte dos sujeitos nucleares (E0I, E04, E06, E07, E I0, E I 5) afirma Que os conhecimentos fornecidos na graduação em enfermagem foram insuficientes para as exigências dos serviços de urgência, principalmente no Que tange ao SAMU. Os entrevistados referem Que após a prestação de cuidados, a troca de experiência, assim como o vocabulário específico ao cotidiano de trabalho, muitas vezes, é dividido informalmente entre os colegas (E01, E03, E07, E13, E15). Esse aprendizado constante Que emerge na fala dos entrevistados faz parte da socialização secundária condicionada às relações de trabalho de um determinado contexto $^{(16)}$.

O fato de executarem um serviço interessante e desafiador motivou a maioria dos sujeitos nucleares (E01, E03, E05, E06, E09, E I I, E15) a ingressar no SAMU. Em contrapartida, a dificuldade em fazer parte deste grupo e a pouca receptividade de alguns colegas enfermeiros veteranos foram enfatizadas por Quatro enfermeiros entrevistados (EOI, EI0, EI3, EI5).

\section{Identidade real e virtual dos enfermeiros de um SAMU}

Na percepção da maioria dos entrevistados, para ser enfermeiro do SAMU o profissional deve, além de gostar de trabalhar com urgência (E04, E05, E06, E07, E08, EI2, E 18), estar sempre se aperfeiçoando (E02, E03, E04, E06, E07, El0, El2, El4, EI5, E17, E19, E20). Além de possuir experiência e habilidade técnica (E03, E05, E07, El0, EI I, EI3, E20), deve ter boa vontade e interesse em crescer (E09, El0, EI I, EI3, El6, El7, El8, E20), demonstrar dedicação e compromisso com o serviço (E02, E05, E08, E 12, E 16), agilidade e objetividade na avaliação dos pacientes e na realização de procedimentos (E03, E06, E08, E12, E13, 
E14, E 15). Também, deve ter autocontrole (E01, E03, E09, EI0, $E 12, E 14, E 15, E 16, E 20)$ e adaptar-se às adversidades e aos diferentes locais de atendimento e com os colegas da equipe de trabalho (E05, E08).

Os procedimentos assistenciais de maior complexidade e a organização do cenário de cuidar constituem as principais atividades desenvolvidas pelos enfermeiros em seu cotidiano de trabalho.

Você recebe o plantão do colega, você confere a ambulância, confere os materiais. Antes vê se realmente está tudo em ordem. É, realmente, você aguarda, você estuda, você lê, você descansa e você aguarda até Que tenha chamado. No momento em Que tenha chamado você se entrega de corpo e alma. Então, você, de você tudo dá para aquele momento. (EI5)

Os atos de pertença descritos pelos sujeitos nucleares apontam para uma identidade real ${ }^{(13)}$, caracterizada por um profissional Que conhece a forma global das ações desempenhadas no SAMU, participa dela, gosta do serviço e das atividades que realiza e está sempre buscando capacitação e o aperfeiçoamento profissional. Ele se cobra muito e se desdobra para superar e adaptar-se às adversidades peculiares das atividades do SAMU. A proximidade com as práticas assistenciais e a oportunidade de não delegá-las a outros membros da equipe constituem suas diferenciações.

Observe-se Que um enfermeiro (EOI) se sente realmente como tal por poder assistir diretamente o paciente e por não ter de se envolver tanto com as Questões burocráticas frequentemente associadas ao contexto hospitalar.

A gente é muito enfermeiro mesmo, né? Quando você trabalha, você que tem que fazer. Então, você realmente é enfermeira. Você lida com o paciente o tempo inteiro. Então, você não se perde em coisas burocráticas. (...) Se você trabalha em um ambiente hospitalar, você está preocupado com outras coisas, mas Quando você vai para um ocorrência efetivamente, você é o enfermeiro. Você lida diretamente. (E0I)

A apropriação de valores do grupo Quanto dos processos de identificação e comparação entre membros traduz a transação subjetiva na busca por uma identidade percebida como positiva de pertencimento e reconhecimento profissional. Apesar de se constituir um serviço novo, a experiência profissional é correlacionada a um ato de pertença por seus membros ${ }^{(13)}$.

Seguindo a lógica de se tentar conhecer o enfermeiro sob a perspectiva de seus sujeitos relacionais, perguntou-se aos sujeitos secundários como é, de fato, o profissional enfermeiro Que trabalha no SAMU. Considerando-se seus relatos, a identidade virtual destes atores sociais pode ser caracterizada por profissionais diferenciados (E20), experientes (E09, EI2, E20), conhecem tudo da unidade (E09, E 17, E20) e estão sempre envolvidos com Questões relativas ao aprendizado e à capacitação (E 12, E20). Estes atos de atribuição reafirmam a proposição de Que a enfermagem é uma profissão em transição, na Qual seus agentes buscam conQuistar progressivamente novas funções, competências e autonomia, e tentam acompanhar padrões de formação cada vez mais elevados e diferenciados ${ }^{(1)}$.

[...] são enfermeiros diferenciados e Que correm muito atrás. Eu vejo quase todos os enfermeiros da equipe. Eu acho que isso é bom porque vai contagiando. Quase todos correm atrás de mestrado, de doutorado. Quase todos são professores. Então isso é muito importante. Então, Quando eu estou em contato com o auxiliar de enfermagem em outros locais, em outros serviços, todos elogiam, porQue a maioria são alunos desses profissionais. Então, isso é muito bom. Então, como a maioria já tem esse ritmo de vida, Quando entra um outro a tendência de ele falar: "espera aí, para mim não sair dessa, que tem de ser bom igual aos outros". Então, eu acho admiro isso de eles estarem sempre correndo atrás de estudar isso e aquilo. (E20)

Por outro lado, os sujeitos relacionais definem enfermeiro do SAMU como um profissional solitário, de pouco relacionamento, tanto com os técnicos de enfermagem Quanto com os demais enfermeiros. Assim como na identidade virtual, os enfermeiros afirmaram fazer parte de um grupo grande, cujos membros estão distantes, principalmente Quando se trata de equipes diferentes, sendo Que a solidão foi associada ao crescimento do serviço e à forma descentralizada de organização. A estes fatores, acrescentase a tomada de decisões de forma verticalizada e ao gerenciamento distante Que se apresenta como uma característica marcante deste serviço (E05, EI3).

O enfermeiro ele fica muito sozinho. É um enfermeiro no plantão de $12 \mathrm{~h}$ e um enfermeiro de uma USA. Ele não tem contato com o enfermeiro da outra USA, porQue elas ficam em bases diferentes e normalmente a referência de enfermagem do plantão ter um enfermeiro Que fica na Central, na Unidade de Suporte Avançado da USA OI e os enfermeiros Que ficam nas outras USAs eles encontram uns com os outros por acaso na Central de Regulação Quando vai repor material ou nos hospitais Quando alguém está levando vítima e encontra com outro colega ou passagem de plantão. Então, o enfermeiro passa o plantão para o colega fala Que é Que aconteceu no plantão, do Que é Que precisa repor. Mas, assim, a relação é muito distante. Então, não digo Que é amigo, é lógico que não. É profissional, mas é muito distante o enfermeiro. (...) A equipe de enfermagem fica assim, um enfermeiro em cada plantão, isolado, segue separado, um gelo, uma pedrinha de gelo em cada plantão! A equipe de técnicos de enfermagem lá longe na USB não sabe nem o nome do enfermeiro Que está de plantão. (E I 8)

Note-se, ainda, Que as relações de trabalho são marcadas pelas relações de gênero e de poder, pela cooperação na superação de dificuldades, pela troca de conhecimento com profissionais menos experientes e pela busca por reconhecimento recíproco, caracterizando as transações objetivas, Que configuram a identidade virtual do enfermeiro deste $\mathrm{SAMU}^{(13)}$.

\section{CONSIDERAÇÕES FINAIS}

Os resultados desta pesQuisa apontam para um projeto identitário de reconhecimento entre seus membros no Qual os enfermeiros frequentemente se veem obrigados a adotar padrões de comportamento direcionados a preencher a expectativa do outro. O reconhecimento recíproco almejado é conciliado no dia a dia de 
um trabalho visto como prazeroso e, ao mesmo tempo, difícil. Fica claro Que não basta dominar os saberes teóricos adeuiridos nos cursos de capacitação e aperfeiçoamento. O contato com a realidade e a aprendizagem construída diariamente no SAMU com a troca de experiências exercem papel fundamental na construção identitária destes enfermeiros. Os sujeitos nucleares consideram importante ter um conhecimento mais nivelado, Que, muitas vezes, é dividido com profissionais médicos menos experientes, contribuindo, assim, para uma conduta mais assertiva, com seu processo de aprendizado e também com uma contribuição diferenciada para a construção de um projeto identitário peculiar nesse espaço de trabalho.

Foram encontradas divergências nos relatos Quanto às Questões associadas aos relacionamentos entre os enfermeiros e os demais integrantes do SAMU. Apesar da conotação de tranquilidade e da integração ressaltadas por alguns, outros depoimentos revelaram a existência de conflitos referentes às trajetórias destes profissionais e Que influenciam sobremaneira seu processo identitário neste contexto de atuação.
Espera-se Que os resultados deste trabalho contribuam para Que enfermeiros e outros membros da equipe de saúde reflitam sobre sua prática, principalmente no Que concerne às relações de trabalho Que têm desenvolvido diariamente. Note-se Que os discursos sinalizaram para a necessidade de relações hierárquicas mais horizontalizadas e de realização de reuniões mais frequentes, não apenas de cunho administrativo, mas também científico e de integração.

Diante da escolha, limitante por definição, de um determinado SAMU para realização da pes@uisa apresentada, da ampliação de frentes de trabalho do próprio SAMU e das perspectivas pessimistas de futuro verbalizadas por alguns enfermeiros em face das constantes transformações pelas Quais vêm passando sua profissão, acrescidas das relações de poder reveladas e da luta pela Quebra do paradigma de pouca autonomia e valorização profissional, sugere-se Que pesquisas que abordem e relacionem tais temáticas possam ser desenvolvidas em contextos similares de atuação destes - os enfermeiros - e outros profissionais da saúde.

\section{REFERÊNCIAS}

1. Abreu WC. Identidade, formação e trabalho: das culturas locais às estratégias identitárias dos enfermeiros. Estudo Multicasos. Lisboa: Educa; 2001.

2. Araújo Netto LFS, Ramos FRS. Enfermeiro: o papel Que se define nas relações conflituosas. In: Anais do $8^{\circ}$. Simpósio Brasileiro de Comunicação em Enfermagem; 2002 may 2-3; São Paulo (SP), Brasil. São Paulo: Escola de Enfermagem de Ribeirão Preto; 2002.

3. Brito MIM. A configuração identitária da enfermeira no contexto das práticas de gestão em hospitais privados em Belo Horizonte [tese]. Belo Horizonte: Faculdade de Ciências Econômicas, Universidade Federal de Minas Gerais; 2004.

4. Campos PFS, Oguisso T. A Escola de Enfermagem da Universidade de São Paulo e a reconfiguração da identidade profissional da enfermagem brasileira. Rev Bras Enferm 2008; 6I(6): 892-8

5. Gomes AMT, Oliveira DC. A auto e heteroimagem profissional do enfermeiro em saúde pública: um estudo de representações sociais. Rev Latino-am Enfermagem 2005; 13(6): 1011 I-8.

6. Conselho Federal de Enfermagem (BR). Resolução COFEN n. 260 de 12 de julho de 2001. Fixa as Especialidades de Enfermagem. [citado em 2008 Dez 02]. Disponível em: http:/ /www. corensp.org.br/resolucoes/Resolucao260.htm.

7. Ito EE, Peres AM, Takahashi RT, Leite MMI. O ensino de enfermagem $e$ as diretrizes curriculares nacionais: utopia $x$ realidade. Rev Esc Enferm USP 2006; 40(4): 570-5.

8. Ministério da Saúde (BR). Portaria n. 2.048 de 5 de novembro de 2002. Aprova o regulamento técnico dos sistemas estaduais de urgência e emergência. Política Nacional de Atenção às Urgências. Brasília: Ministério da Saúde; 2004.

9. Cortez MSM. A dependência do paciente portador de traumatismo cranioencefálico por acidente automobilístico: um desafio para a família [dissertação]. Belo Horizonte: Escola de Enfermagem, Universidade Federal de Minas Gerais; 2003.

10. Florêncio VB, Rodrigues CA, Pereira MS, Souza ACS. Adesão às preocupações padrão entre os profissionais da equipe de resgate pré-hospitalar do Corpo de Bombeiros de Goiás. Rev

Eletr Enferm 2003; 5(1): 43-8.

11. Hora EC, Sousa RMC. Os efeitos das alterações comportamentais das vítimas de trauma crânio-encefálico para o cuidador familiar. Rev Latino-am Enfermagem 2005; I3(I): 93-8.

12. Araújo Netto LFS, Ramos FRS. Considerações sobre o processo de construção da identidade do enfermeiro no cotidiano de trabalho. Rev Latino-am Enfermagem 2004; I2(1): 50-7.

13. Dubar C. A socialização: construção das identidades sociais e profissionais. 2a ed. São Paulo: Porto Editora; 1997.

14. Vieira A. Identidade e crise de identidade: reflexões conceituais. In: Vieira A, Goulart IB, coordenadores. Identidade e subjetividade na gestão de pessoas. Curitiba: Juruá; 2007. p. 55-74.

15. Hall S. A identidade na pós-modernidade. $1 \mathrm{I}^{\mathrm{a}} \mathrm{ed}$. Rio de Janeiro: DP\&A; 2006

16. Berger PL, Luckmann T. A construção social da realidade. $20^{\mathrm{a}}$ ed. Petrópolis: Vozes; 1985.

17. Machado HV. A identidade e o contexto organizacional: perspectiva de análise. Rev Adm Contemp 2003; 7 (esp): 5 I-73.

18. Woodward K. Identidade e diferença: uma introdução teórica e conceitual. In: Silva TT, organizador. Identidade e diferença: a perspectiva dos estudos culturais. $7^{\mathrm{a}}$ ed. Petrópolis: Vozes; 2007.

19. Sainsaulieu R. Sociologia da empresa. Organização, cultura e desenvolvimento. Lisboa: Instituto Piaget; 1997.

20. Ramos VO, Sanna MC. Inserção da enfermeira no atendimento pré-hospitalar. Rev Bras Enferm 2005; 58(3): 355-60.

21 . Ministério da Saúde (BR). Rede Nacional SAMU 192. Etapas, localidades e cidades atendidas. Brasília; 2008. [citado em 2008 Set 30]. Disponível em: http://portal.saude.gov.br/portal/saude/ visualizar_texto.cfm?idtxt $=23745 \&$ janela $=1$.

22. Coelho MI, Figueiredo NMA, Carvalho V. Tipos de cuidado em emergência. In: Figueiredo NMA, Vieira AAB. Emergência: atendimento e cuidados de enfermagem. São Paulo: Yendis; 2006. p. $217-234$. 
Avelar VLLM, Paiva KCM.

23. Zapparoli AS, Marziale MH. Risco ocupacional em Unidades de Suporte Básico e Avançado de Vida em Emergências. Rev Bras Enferm 2006; 59(1): 41-6.

24. Martins PPS, Prado ML. Enfermagem e serviço de atendimento pré-hospitalar: descaminhos e perspectivas. Rev Bras Enferm 2003; 56(1): 71-5.

25. Yin RK. Estudo de caso. Planejamento e métodos. $3^{\text {a }}$ ed. Porto Alegre: Bookman; 2005.

26. Jick TD. Mixing Qualitative and Quantitative methods: triangulation in action. Admin Sci Quarterly 1979; 24(4): 602I I.
27. Collis I, Hussey R. Pesquisa em Administração. São Paulo: Bookman; 2005.

28. Bardin L. Análise de Conteúdo. $3^{\mathrm{a}}$ ed. Lisboa: Edições 70; 2004.

29. Minayo MCS. O desafio do conhecimento: pesquisa Qualitativa em saúde. 7a ed. São Paulo: Hucitec; 2000.

30. Ministério da Saúde (BR). Conselho Nacional de Saúde. Resolução n. 196 de 10 de outubro de 1996. Aprova as diretrizes e normas regulamentadoras de pesquisas envolvendo seres humanos. Informe Epidemiol SUS 1996; 5(2). 